\title{
DEVELOPMENT OF AN OPTICAL TECHNIQUE FOR SCAN THE SOIL AFTER THE CONTACT WITH WHEELS
}

\author{
Diego Eduardo Costa Coelho \\ Federal University of Lavras (UFLA), Engineering Dept., P.O. Box 3037, ZIP Code 37,200-000, Lavras-MG, Brazil
}

\author{
Elisângela Ribeiro \\ Federal University of Lavras (UFLA), Engineering Dept., P.O. Box 3037, ZIP Code 37,200-000, Lavras-MG, Brazil \\ Corresponding author: elismar1952@hotmail.com
}

\section{Roberto Alves Braga Junior}

Federal University of Lavras (UFLA), Engineering Dept., P.O. Box 3037, ZIP Code 37,200-000, Lavras-MG, Brazil

\begin{abstract}
Soil is a collection of natural bodies, that are made of solid parts, liquid and gas, three-dimensionally and formed by mineral sand organic materials, containing living matter one of the mantle surface of the planet, providing the development of agriculture that is essential and irreplaceable to human life. In agriculture, the use of mechanization arms to increase productivity, once the global population grows everyday, increasing the demand for food and avoiding deforestation for opening new agricultural frontiers. The use of machinery in agriculture requires full knowledge of its operation, adjustments and maintenance, as well as the compatibility of soil-working machine, otherwise it may cause impacts to the soil and therefore to the environment. So it is critical to understand the effects that the tires of the tractor can cause during the transit of tractors through agricultural areas, giving preference to monitoring techniques that avoid contact with the soil and demands great consumption of time and labor. This study evaluated the interferometric technique as a potential alternative to traditional manual processes or high cost equipment and proposed a protocol to be used in the field besides testing the methodology of a laser scanner. The results showed the feasibility of the proposed technique in the laboratory and in the field in addition to copy the soil 3D profile and identify the deformations caused by the tread.
\end{abstract}

Index terms: MOIRÉ; Deformation; Pressure distribution.

Received: November, 05, 2018 - Accepted: February, 25, 2019

\section{INTRODUCTION}

As discussed by Balbinot Junior et al. (2009) the use of machines and implements tends to increase agricultural productivity, due to the increase of the operational capacity of work, replacing the manual work and reducting the final cost. However, the success of agricultural mechanization is linked to the full knowledge of implements and tractors, their adjustments, their appropriate field operatin conduction and also their wheel interaction with the soil.

The loads of the wheels and agricultural implements applied in the soil produce tensions at the soil-tire interface and soil-implement in surface and in depth, respectively (Silva et al., 2003). These stresses compact the soil layers when loads outweigh the internal resistance of the soil causing changes in its physical properties (Horn
1988; Horn and Lebert, 1994). Thus, continuous and inadequate traffic of agricultural machinery and implements can lead to soil degradation, with physical and mechanical alterations of the soil structure, compromising the availability of water and nutrients to the plants and, consequently, resulting in a reduction of productivity (Wiermann et al., 1999; Wiermann et al., 2000; Silva et al., 2003). In this context, understanding the soil-machine interaction is important to develop or improve methods of agricultural management, which involves the quantification of the deformations caused by machines' traffic in agricultural soil.

Currently, the traditional methods for evaluation and quantification of soil deformation are the roughness of rods and the use of gypsum. The rugosimeter of rods allows the evaluation of the roughness oriented through pin meters 
(Garcia Moreno et al., 2008) in the furrows and elevations formed by implements used in soil preparation, sowing, application of crop protection products and harvesting (Burwell et al., 1963; Allmaras et al., 1966; Currence and Lovely, 1970). The use of gypsum enables the construction of topographic profiles or contours by means of molds or cutouts (Dexter etal., 1982), providing the quantification of the depth of the soil profile through plaques formed with the representation of the surface in question (Botta et al., 2009). These are low cost methods, but they require a lot of manual activity, which makes it time consuming and susceptible to human error, providing limited data for scanning and causing contact and interference to the measured soil.

The optical techniques in turn allow a nondestructive approach without contact with the ground, besides avoiding manual measures. An example is the case of stereo photogrammetry (Taconet and Ciarletti, 2007). In this context the interferometria methods such as Moire can determine the profile of objects (Hertz et al., 2005) with a versatile, agile and easy way to collect and manipulate data. The interferometric technique that analyzes the Moire phenomenon is the basis for many scanners, such as the laser scanner. This technique is notable for being a non-invasive and non-destructive method, being an alternative for soil profile studies, such as agricultural machine traffic, which can cause overloading of the soil and possible damage to the development of crops (Lino and Dal Fabbro, 2004) and (Mckenzie, 2015). This interferometric technique can be seen in applications such as the estimation of the surface area of broilers (Silva, 2007), in the measurementof the volume of macaúba fruit (Costa et al., 2016), in topography of eggs, estimating the mass of the yolk, white, bark and all the egg (Silva et al., 2011) and also in the investigations of surface profile in mechanical prototypes, seeking low costs and flexibility (Gomes et al., 2009), besides the postural analysis of humans (Fernandes et al., 2003).

The present work aimed to present a methodology for digitizing deformed soils by the passage of a tractor using an optical interference technique limited to one digital tractor using an optical interference technique limited to one digital camera and using the correction of perspectives through image processing.

\section{MATERIAL AND METHODS}

The works were conducted in the laboratory, for adjustment and calibration and, later, extended to the field. In order to reach the proposed objective, the experiment was divided into three stages:

- Application of the methodology proposed in the analysis of soil deformations in a controlled environment (laboratory);

- Evaluation of deformations in the ground adapting a line laser for lighting;

- Validation of the proposed methodology in field.

\section{In laboratory conditions}

The proposed method using optical interference technique limited to only one digital camera and digital perspective correction was first conducted in a optical laboratory. It was used a Canon EOS 400D digital camera equipped with a set of lenses to amplify the object under study, a multimedia projector from the Epson brand Power Lite model S8+/W8+, a notebook Acer (ASPIRE 5536) with Dual-Core processor and 3GB of RAM and a piece of wood in rectangular

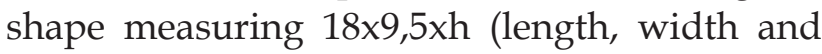
height respectively).

The grids were projected by a multimedia device on the object and the images were captured by a digital camera located at $1.30 \mathrm{~m}$ from the surface where the object was placed at an angle of $39.62^{\circ}$ to the ground plane as present in Figure 3 . The projector at was positioned $1.40 \mathrm{~m}$ from the surface at an angle of $32.17^{\circ}$ to the ground and with a distance between the projectou and the câmera of $40 \mathrm{~cm}$.

The images were processed in Scilab version 4.0 software, using a routine that is responsible for processing the Moiré technique. Along with Scilab you need to use SIVP and Image Magic 6.2.5 support libraries that are known as toolboxes responsible for the processes of the images in the software. Then, they were adjusted by the methodology cited by Gomes (2009) that converts pixels to millimeters in the $x, y$ and $z$ axes, using the known piece of wood.

Subsequent, the correction of the warped 3D images obtained were done using the unwarp 
method proposed by Saalfeld and Tomancák (2008) as an ImageJ plugin. The unwarping procedure is based on a nonlinear and non-revecrible transformation using the leasts squares method.

The warped 3D image resulted from the optical interferometric method and distorted due to the perspective of only one camera received milestons as well as a template image that does not have the perspective distortion.

With the experimental arrangement and the methodology for the correction of irregularities in the defined digitized surface. The procedure in the lab was conducted in two steps, the digitalization of a known object, a piece of wood, and the digitalization of a plan tom soil. The digitalization of a piece of wood was made to adjust the set up to the soil. The adjustments were related to the best distances of the devices (projector a camera) to get a reliable 3D image of the wood, and to get the calibration value to transforma pixel to $\mathrm{mm}$. The perspective unwarping was soil deformations caused by the tyre and its claws. The perspective unwarping was also used in the piece of wood in order to replicate it in the same conditions in the soil.

The analysis was carried out using the projection Moire technique, using the same adjustment of devices including the projected grid as illustrated in Figure 1. In the laboratory, the deformation caused by the tyre claws in the plan to soil was created manually respecting the scale expected in the field.

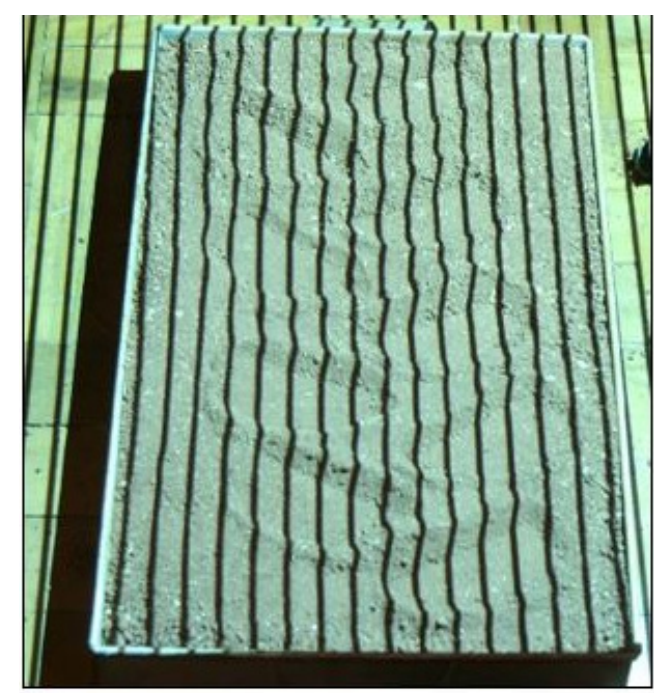

Figure 1: Simulation of the claw marks of a tractor tire.

\section{Using a laser line}

To test the possibility of using a line laser in substitution of the projector, a robotic cell was used with an arm articulated with the laser emitting a line fixed in its claws, with the same relative angle between the camera and laser line was adjusted in order to create the some respective in vertical and horizontal lines.

The robot arm made controlled shifts, so that the line traveled through the metal box containing the ground with simulated marks of a tractor tire, forming a projected grid as verified in Figure 2.

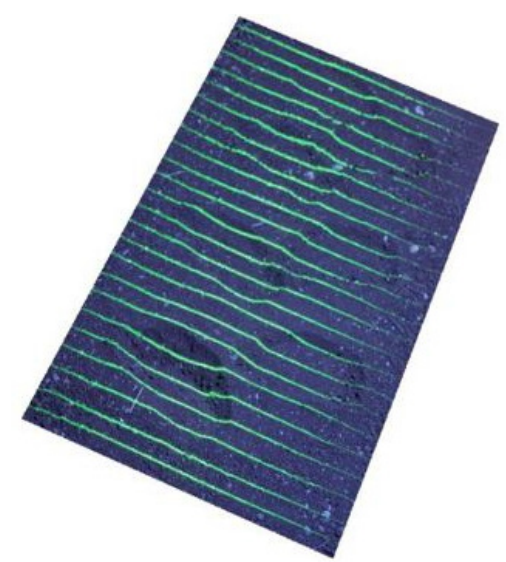

Figure 2: Projected lines of a laser in a plan tom soil with simulation works.

\section{Conducting the experiment in the field}

After adjustment and calibration of the technique in the laboratory, it was taken to the field. The validation of the methodology proposed in the field situation was carried out with the soil characterized as red Latosol, with humidity of $28.8 \%$, granular structure, clayey texture and that was just plowed. Using an Agrale T-4100 tractor, three passes were made on the ground in order to mark the claws of the tires in the soil.

The camera and the multimedia projector have been positioned as shown in Figure 3, with proper camera and projector settings and in accordance with the laboratory tests.

After being captured, the images were edited in the ImageJ software, then using a routine in the software Scilab 4.0.0 was performed the Moiré technique and then made adaptations through the methodology of Gomes (2005) for the conversion of the pixel dimension for millimeters. 


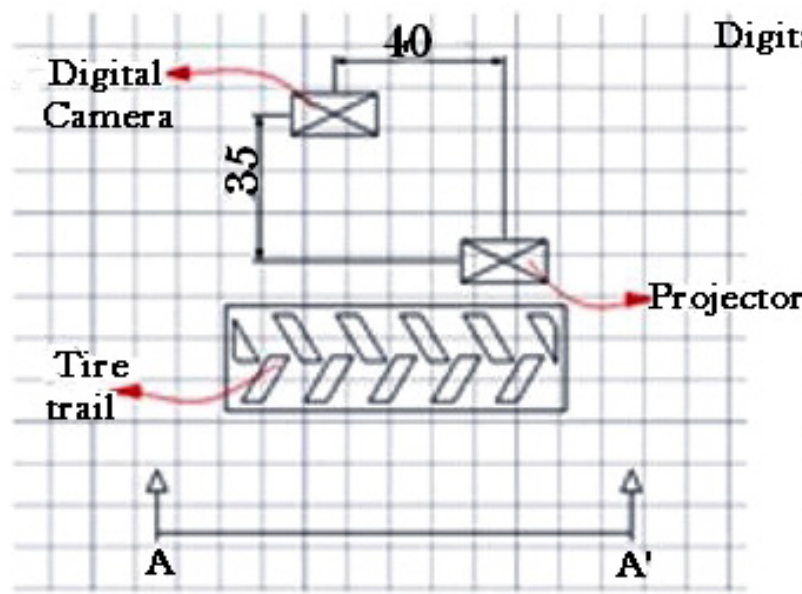

(A)

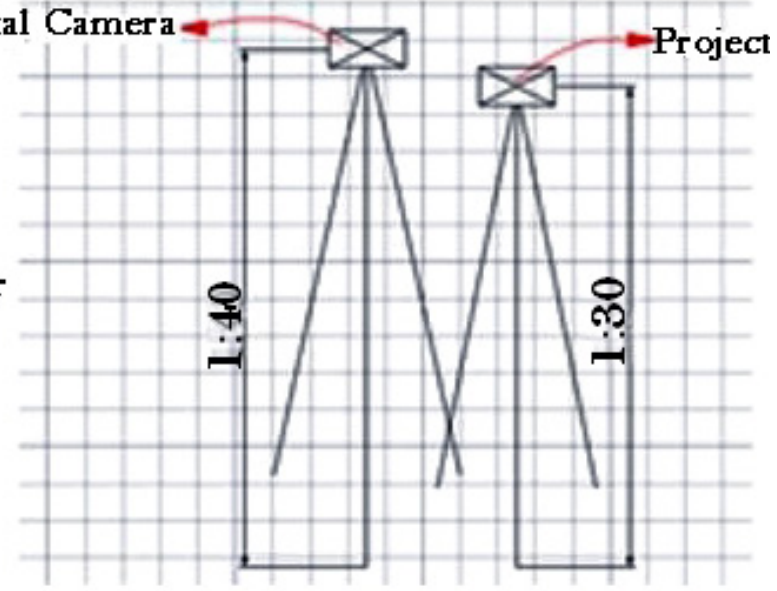

(B)

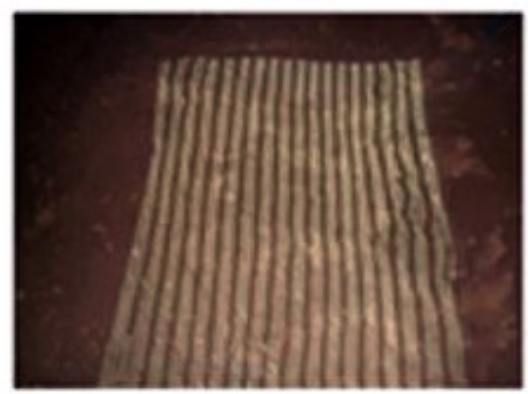

(C)

Figure 3: Top and side views of the layout of the camera, projector and region of interest where the rectangular piece of wood was positioned in the center.

\section{RESULTS AND DISCUSSION}

\section{A protocol definition}

The ideal positioning of the equipment was found using a piece of rectangular wood with known dimensions and close to the expected deformations in the soil.

Twenty offsets were made with the camera and it is verified that the camera should be at an angle of $39.62^{\circ}$ perpendicular to the object and with a vertical height to the ground of $1.40 \mathrm{~m}$ and the projector at a vertical height of $1.30 \mathrm{~m}$.

In Figure 4 one can see the profile of the wood piece after the digitizing with and without the correction made to unwarp the perspective deformation. The correction provided made the profile closer to the real surple, however with different match in the edges caused in this case by the distance of the lines in the grids. It the distance of the lines were smaller the sensitiveness would increase and one could obtain the influence of small granulates in the soil creating a roisy $3 \mathrm{D}$ image.

Moire/Real/Correction

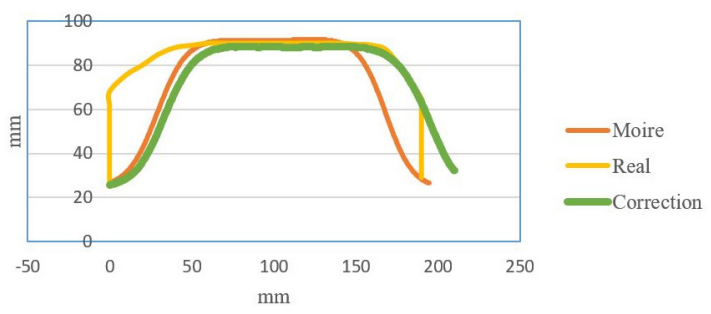

Figure 4: Deformation of the piece of wood referring to the original aspect and to the corrected 3D image.

\section{Application of the methodology in a con- trolled environment}

In Figure 5 it is possible to observe the illumination of a piece of wood and a deformed soil, both with the Moire grids projected on them, as well as the scanned object on the deformed soil. 

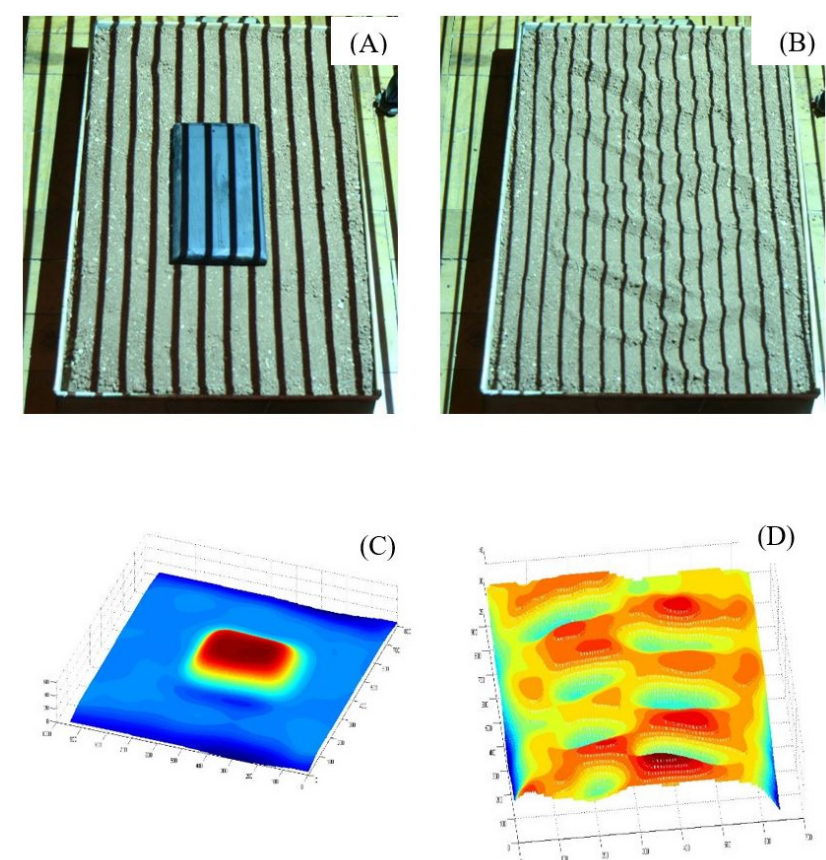

Figure 5: Projection of the grids on a piece of wood (a) and on the deformed soil (b); in the scanned piece of wood (c) and in the digitized deformed soil (d).

The digitized deformations became very clear, showing the simulated deepening of the claws but still in pixels and with the warped aspect due to the perspective. The transformation from pixels to millimeters could be done using the known dimensional of the piece of wood digitization and the unwarping could be used as presented to the wood.

\section{Validation of the methodology proposed in the field}

In the qualitative and quantitative analysis of the load distribution of the tractor on the ground, it was adapted the manufacturer's recommended tire calibration of $90 \mathrm{kPa}$ (13.0 psi) at the rear tyres. The 3D map obtained presented a surface with a variation from an average plan of about $1,15 \mathrm{~mm}$ without the edges which is relatively small in relation to the insufficient Figure 8 and excessive Figure 7 calibration $(6,13 \mathrm{~mm}$ and 2,27 $\mathrm{mm}$ respectively), indicating that the entire tread was used to transfer the weight of the tractor to the ground, and it is verified that the load distribution was uniform as shown in Figure 6.

When the tractor tire was calibrated with excessive calibration, $124 \mathrm{kPa}(18.0 \mathrm{psi})$ at the rear, the standard deviation of the digitized profiles was higher, compared to the normal calibration, presenting a value of $2.27 \mathrm{~mm}$.

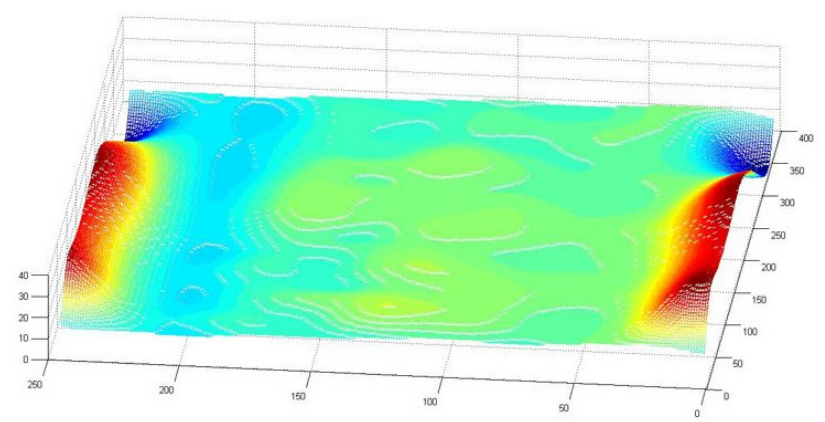

Figure 6: Digital model of soil elevation deformed by Agrale T-4100 tractor with normal calibration of the tyres.

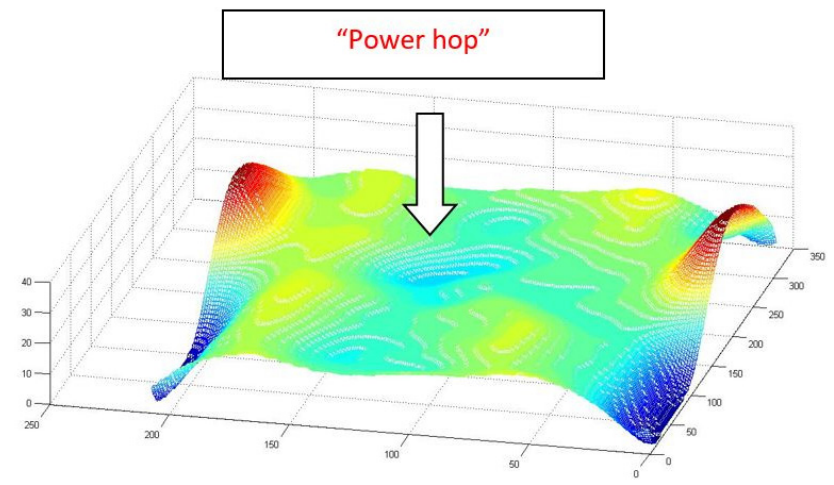

Figure 7: Agrale T-4100 digital tractor elevation model with excessive calibration, showing the power hop phenomenon.

The tractor tire Agrale showed some deeper regions in the middle of the tread, it was due to the excessive pressure, with the weight concentration occurring in the middle of the tread. In addition, since the right side of the tractor had different calibrations in relation to the left side, the phenomenon of "power hop" McKenzie et al. (2016) could be observed since wheels with different calibrations have the different running radius and cause an imbalance in the shaft, which resulted in the deepening due to the oscillation of the tractor, as shown by the digital elevation model of Figure 7.

In the condition of insufficient calibration, the standard deviation obtained was of $6.13 \mathrm{~mm}$, when calibrated with pressure 55,2 $\mathrm{kPa}(7,0 \mathrm{psi})$ at the rear, indicating high depth variability in the trail Figure 8. 


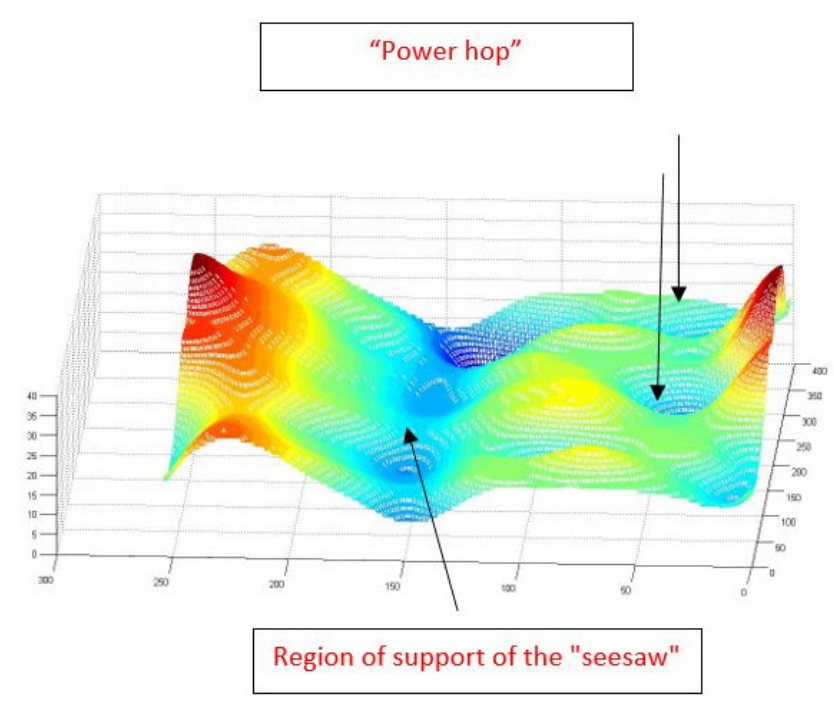

Figure 8: Agrale T-4100 digital bulldozer model with insufficient calibration, highlighting in the external region of the tire the phenomenon of Power hop and, in the internal region of the tire, an excessive concentration of the support pressure.

In the case of insufficient calibration, tractor is light and the marks it claws of the wheel were not perceived on the ground, due to the high index of slip. This situation obtained the highest standard deviation of the three situations, due to the fact that in the case of insufficient calibration the most requested parts in the tire are the sides of the tread McKenzie et al. (2016). This fact makes the dispersion of the depths larger, because there are two regions with greater depth and a zone of transition between them.

The difference of calibrations of the tires in the two rides also caused, in the insufficient calibration, the presence of the "power hop" depressions also observed by the digitized map, Figure 8.

\section{Line laser test}

In the evaluation of soil deformations by adapting a line laser, it was possible to digitize a piece of wood with known measurements and a deformed soil. In Figure 9, it is possible to see the projected lines and digitizes samples.

In Figure 9 (C) and (D) it is presented the scans of the piece of wood and deformed soil, both in three dimensions, transformed in millimeters, showing the efficiency and potential of the technique when applying to this type illumination. By means of the laser scanner equipment, one can perceive the visual quality provided by the images, due to the degree of quality provided by the laser line compared to the lines of the projector. In this way, the line laser adapted to a structure with a small stepper motor controlled by the computer can do the robotic arm, reducing the costs of using a conventional laser scanner. Another advantage of projection of laser lines instead of structured light is the ability to use it in day time with no influence of the natural light in the process, if the laser presents power enough.
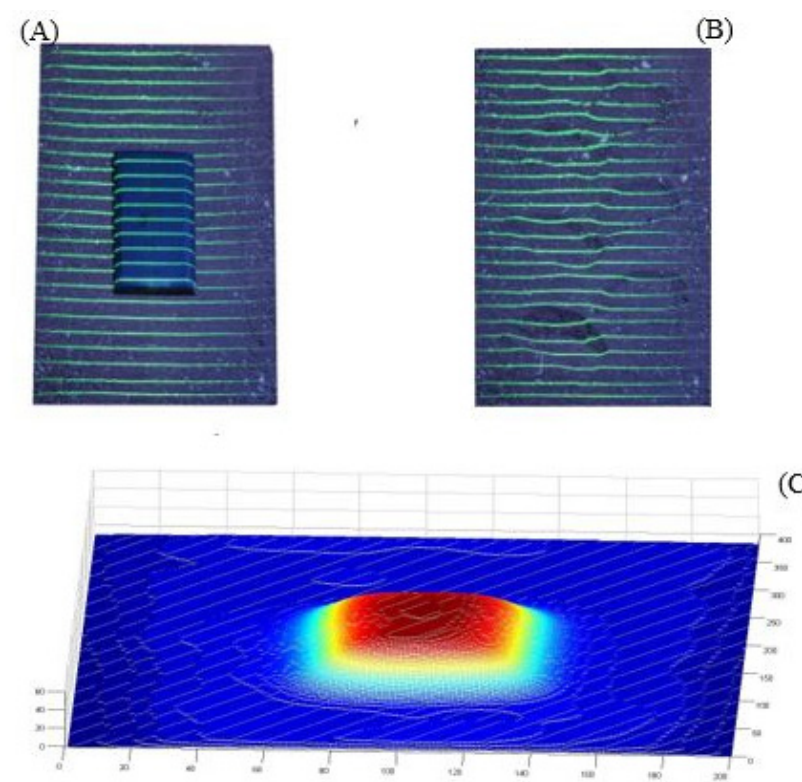

(C)

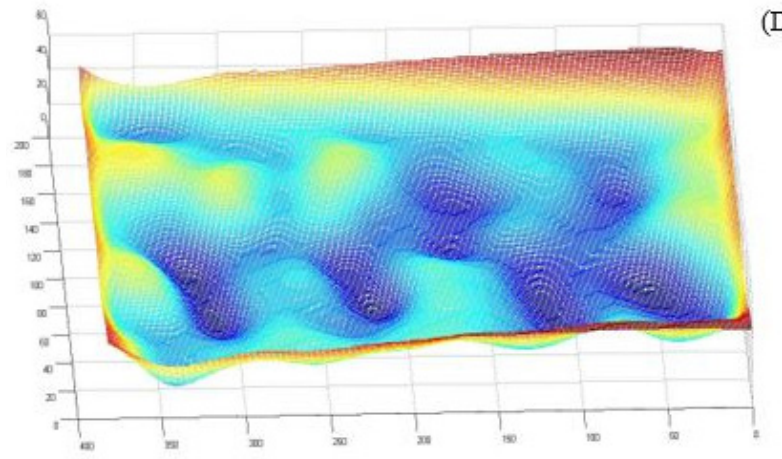

(D)

Figure 9: Projection of the laser lines on the piece of wood (A); in (B), the projection of the laser lines on the deformed ground; in (C), the digitization of the piece of wood and,in (D), the scanning by a laser scanner of deformed soil. 
The corrections of perspective were also conducted, and in Figure 10 it is possible to see the difference of the top views with and without the unwarpping Figure 10 (B) and the data observed according to Figure 10 (A), concluding with a final image with all the original information.

(A)

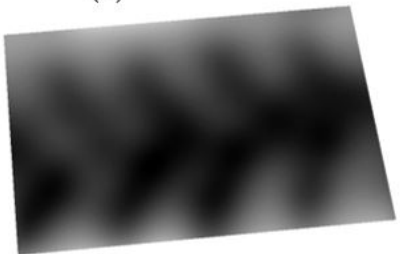

Figure 10: Deformed image (A); in (B) Image after applying the Landmark plugin ImageJ software correspondences.

\section{CONCLUSIONS}

The optical technique based on interference of projeted grids proved to be feasible to digitize of the deformed soil. Due to the potential of the technique, factors such as pressure distribution and Power hopp, were observed and analyzed.

The laser showed to be more efficient compared to the light of the projector for the study in question, due to the better detailing and contour of the surface of the ground and higher ability to show the lines projected when natural light is involved.

Perspective corrections were primordial and essential to minimize deformations observed in the images. The results were satisfactory, with good approximation of reality.

\section{REFERENCES}

ALLMARAS, R. R. et al. Total porosity and random roughness of the inter row zone as influenced by tillage. USDA Conservation Research Report 7, 1966. 22p.

BALBINOT JUNIOR, A. A. et al. Integração lavourapecuária: intensificação de uso de áreas agrícola. Ciência Rural, (39):1925-1933, 2009.

BOTTA, G. F.; TOLONBECERRA, A.; BELLORATOURN, F. Effect of the number of tractor passes on soil rut depth and compaction in two tillage regimes. Soil \& Tillage Research, (103):381-386, 2009.
BURWELL, R. E.; ALLMARAS, R. R.; AMEMIYA, M. A. Field measurement of total porosity and surface microrelief of soils. Proceedings Soil Science Society of America, (27):697-700, 1963.

COSTA, A. G. et al. Measurement of volume of macaw palm fruit using traditional and the digital Moire techniques. Revista Brasileira de Engenharia Agrícola e Ambiental, (20):152-157, 2016.

CURRENCE, H. D.; LOVELY, W. G. The analysis of soil surface roughness. Transactions of the ASAE, (13):710-714, 1970.

DEXTER, A. R.; HEIN, D.; HEWITT, J. S. Macrostucture of the surface layer of a self-mulching clay in relation to cereal stubble management. Soil Tillage Research, (2):251-264, 1982.

FERNANDES, L. F. R. M. et al. Utilização da técnica de Moire para detectar alterações posturais. Revista Fisioterapia e Pesquisa, (10):16-23, 2003.

GARCIA MORENO, R. Shadow analysis: A method for measuring soil surface roughness. Geoderma, (146):201-208, 2008.

GOMES, T. S. et al. Calibração da técnica de Moireaplicada a perfilometria de protótipos mecânicos. Ciência e Agrotecnologia, Lavras, (33):574-579, 2009.

HERTZ, H. et al. Desenvolvimento da técnica de Moire de sombra como alternativa de baixo custo para análise postural. Scientia Medica, (10):16-23, 2005.

HORN, R. The effect of static and dynamic loading on stress distribution, soil deformation and its consequences for soil erosion. In: BLUME, H. P.; FLEISCHHAUER, M.; HEBEI, T. Sustainability, environmental protection. Catena, Publ. CremlingenIn Press, 1998.

HORN, R.; LEBERT, M. Soil compactibility and compressibility. In:SOANE, B. D.; van OUWERKERK, C. Soil compaction in crop production. Developments in Agricultural Engineering, Amsterdam, Elsevier, 1994.

LINO, A. C. L.; DAL FABBRO, I. M. Determinação da topografia de uma fruta pela técnica de Moirede sombra com multiplicação de franjas. Ciência e Agrotecnologia, (28):119-125, 2004. 
MCKENZIE, B. et al. Moire as a novel approach toquantifysoilcompaction. NJF Report, (8):109-112, 2012.

MCKENZIE, B. M. et al. Moire as a low-cost, robust, optical-technique to quantify soil surface condition. Soil \&Tillage Research, (158):147-155, 2015.

SAALFELD, S.; TOMANCÁK, P. Automatic landmark correspondence detection for ImageJ. In: Proceedings of the ImageJ User and Developer Conference, 2008:128-133.

SILVA, G. C. A. et al. Recuperação da topografia de ovos por meio da técnica de Moire e calibração independente. Engenharia Agrícola, (31):211-218, 2011.

SILVA, R. B. et al. O tráfego de máquinas agrícolas e as propriedades físicas, hídricas e mecânicas de um latossolo dos cerrados. Revista Brasileira de Ciência do Solo, (27):973-983, 2003.

TACONET, O.; CIARLETTI, V. Estimating soil roughness indices on a ridge-and-furrow surface using stereophotogrammetry. Soil \& Tillage Research, 64-76, 2007.

WIERMANNN, C. de et al. Effect of various dynamic loads on stress and strain behaviour of a Norfolk sandy loam. Soil \& Tillage Research, (50):127-135, 1999.

WIERMANNN, C. et al. Stress/strain processes in a structured silty loam Luvisol under different tillage treatments in Germany. Soil \& Tillage Research, (53):117-128, 2000. 